\title{
Mycosis Fungoides: Epidemiology in Isfahan, Iran
}

\author{
Farahnaz Fatemi Naeini ${ }^{1}$, Jamshid Najafian ${ }^{2}$, Mansoor Salehi ${ }^{3}$, Zahra Azimi $^{4,5^{*}}$, Parvin Rajabi $^{6}$ \\ ${ }^{1}$ Skin Diseases and Leishmaniasis Research Center, Isfahan University of Medical Sciences, Isfahan, Iran; ${ }^{2}$ Isfahan Cardiovascular \\ Research Center, Isfahan Cardiovascular Research Institue, Isfahan University of Medical Sciences, Isfahan, Iran; ${ }^{3}$ Department of \\ Genetics and Molecular Biology, Medical School, Isfahan University of Medical Sciences, Isfahan, Iran; ${ }^{4}$ Skin and Stem Cell Re- \\ search Center, Tehran University of Medical Sciences, Tehran, Iran; ${ }^{5}$ Isfahan University of Medical Sciences, Isfahan, Iran; ${ }^{6}$ Isfahan \\ University of Medical Sciences, Isfahan, Iran. \\ Email: ${ }^{*}$ z_azimi@edc.mui.ac.ir
}

Received January $25^{\text {th }}, 2012$; revised February $28^{\text {th }}, 2012$; accepted March $13^{\text {th }}, 2012$

\begin{abstract}
Background: Mycosis Fungoides (MF) is the most common and indolent form of Cutaneuse T-cell Lymphomas (CTCL), that usually occurs in old adults. Objectives: To determine epidemiologic features and patients characteristics of MF in Isfahan (Iran). Methods: We performed a retrospective study in MF clinic of alzahra hospital that is the main center for treatment of MF patients in Isfahan (Iran) and evaluated clinicopathologic features. Results: In 3 years 25 patients were referred to Alzahra MF clinic. 18 patients diagnosed as MF. Seven (38.9\%) patients were male and $11(61.1 \%)$ were female with male to female ratio of 1:1.57. The mean age of patients was 41.06 years. $88.9 \%$ of our patients were in stages IA and IB. Conclusion: Most of our patients presented in early stages that were similar to other studies, while male: female ratio is different from other studies.
\end{abstract}

Keywords: Mycosis Fungoides; Epidemiology; Clinical Features; Iran

\section{Introduction}

Mycosis Fungoides (MF) is a disease of lymphatic tissues with primary involvement of the skin and is the most common and indolent form of Cutaneuse T-cell Lymphomas (CTCL), followed by Sezary Syndrome. Initially, MF presents as a round or ovoid, flat erythematous or eczematous patch lesion, with or without fine scales [13].

MF usually occurs in old adults, with a median age between 55 and 60 years and a 2:1 male to female ratio $[4,5]$.

The diagnosis of MF in its patch or early plaque phase is often difficult, either because MF mimic other cutaneuse disorders such as benign dermatoses or discordance between clinical and pathologic findings [6,7].

Etiology of MF is unknown, however some studies suggested a causative role of environmental exposure to chronic antigenic stimulation, but they have not been substantiated by subsequent studies [8-10].

MF is a relatively rare disease and there is no registration system for this disease in Iran and therefore there is not enough epidemiologic information about MF in our country. The aim of this study is to collect epidemiologic information as well as patient characteristics and clinicopathologic features of MF in our region, Isfahan, Iran.

${ }^{*}$ Corresponding author.

\section{Patients \& Methods}

We performed a retrospective study in Alzahra hospital of Isfahan that is the main center for diagnosis and treatment of patients suspected in MF.

Our study included 25 patients that were suspected in MF and referred to Alzahra MF clinic in three years from 2007 to 2010.

For establishing the diagnosis each patient reexamined clinically and the type of skin lesions (including patch, plaque, tumor, erythroderma, ...), percentage of skin involvement as well as location of lesions were determined. We used WHO classification of tumours of haemopoietic and lymphatic tissue (2008) to classify our cases [11]. For staging TNMB classification system (2007) was employed that is the newest classification system for MF and Sezary Syndrome [12].

Haematoxylin and eosin-stained slides reviewed by pathologist. Immunohistochemical (IHC) stains for basic T-cell markers CD4, CD8, CD3, CD5, CD7, CD30, and CD45RO evaluated where needed. Also fresh or paraffin-embedded tissues checked for T-cell clonality, using TCR gamma gene rearrangement assay kit (In Vivo Scribe technologies, USA) [13].

For each patient a profile including all related information, was collected. Among this were age, gender, marital status, address, physical examination, type of skin 
lesions, lesion distribution, tumor stage as well as results of pathology and molecular biology studies.

Cases other than MF were excluded from the study and patient's forms were reviewed.

After data collection statistical analysis was performed by SPSS soft ware version 19 .

\section{Results}

During 3 years 25 patients were referred to Alzahra MF clinic. After clinical, histological and molecular clonality reevaluation, 18 patients diagnosed as MF. Seven (38.9\%) patients were male and $11(61.1 \%)$ were female with male to female ratio of $1: 1.57$. The mean age of patients was 41.06 years [median, 34.5 years; range, 25 - 86; standard deviation (SD), 17.9], and that was 41 for male and 41.09 for female patients.

Seven $(38.9 \%)$ patients presented with patch, one of them had hypopigmented patch, $3(16.7 \%)$ with plaque, 6 $(33.3 \%)$ had combination of patch and plaque and the disease in $2(11.1 \%)$ patients were in tumor stage.

We performed $\mathrm{T}$-cell receptor gene rearrangement studies for all patients. In patients were diagnosed as MF,
$11(61.1 \%)$ were positive \& $7(38.9 \%)$ were negative.

Using TNM classification system, 8 patients $(44.4 \%)$ were in stage IA, 8 patients $(44.4 \%)$ were in stage IB and $2(11.1 \%)$ in ПВ.

Exposure to radiation or chemicals, lesion distribution, pathologic and IHC results of patients are shown in Table 1. Twelve $(66.66 \%)$ patients had no remarkable exposure to sunray or chemical agents.

Fourteen $(77.8 \%)$ of the cases were married. Most of the patients $(83.3 \%)$ had educational degree of diploma or less. $81.8 \%$ of women were housekeepers and most of men were workers $(42.9 \%)$ and salesmen $(28.6 \%)$.

Seven patients $(38.9 \%)$ were from Flavarjan and suburb, a small city close o Isfahan, and 5 (27.8\%) from Isfahan city.

\section{Discussion}

The current study represents a retrospective review of patients referred to Alzahra MF clinic in three years, including 18 patients confirmed as MF.

There is a male predominance in almost all of studies on CTCLs and MF with a male: female ratio of 1.30 to

Table 1. patients' characteristics.

\begin{tabular}{|c|c|c|c|c|c|c|}
\hline Patient No./sex/age & $\begin{array}{l}\text { Exposure to } \\
\text { chemicals or radiation }\end{array}$ & Lesion distribution & Stage & Pathology & IHC & TCR \\
\hline 1/M/86 & Sun ray chemical agents & Trunk \& lower limbs & ПВ & $\begin{array}{l}\text { Panniculitis like T-cell } \\
\text { lymphoma }\end{array}$ & $\mathrm{MF}$ & + \\
\hline $2 / F / 34$ & no & Trunk \& lower limbs & IB & $\mathrm{MF}$ & MF & - \\
\hline $3 / \mathbf{F} / 54$ & Sun ray & Buttocks, right groin, lower limbs & IA & MF & MF & - \\
\hline $5 / M / 35$ & no & Trunk, lower limbs & ПВ & MF & $\mathrm{MF}$ & - \\
\hline $6 / F / 51$ & no & Axilla, groin & IA & MF & MF & + \\
\hline $7 / \mathrm{M} / 26$ & HCL smoke & Head \& neck, trunk, upper \& lower limbs & IA & MF & MF & + \\
\hline $8 / \mathbf{M} / 52$ & Sun ray & Trunk, upper \& lower limbs & IB & Parapsoriasis & MF & + \\
\hline $9 / \mathbf{F} / 25$ & no & Buttocks, upper \& lower limbs & IA & MF & MF & + \\
\hline $10 / F / 30$ & no & Lower limbs & IA & MF & MF & + \\
\hline $11 / M / 28$ & no & Trunk, upper \& lower limbs & IB & $\mathrm{MF}$ & MF & + \\
\hline $12 / F / 50$ & no & Face, back, lower limbs & IB & MF & ND & - \\
\hline 13/F/80 & no & Buttocks, upper \& lower limbs & IB & MF & MF & + \\
\hline $14 / F / 29$ & no & Trunk, upper \& lower limbs & IA & Chronic dermatitis & MF & + \\
\hline $15 / F / 29$ & no & Head, trunk, upper \& lower limbs & IB & MF (folliculotropic) & MF & - \\
\hline $16 / \mathrm{M} / 30$ & Oil colors & Trunk, upper \& lower limbs & IA & $\mathrm{MF}$ & $\mathrm{MF}$ & + \\
\hline 17/M/30 & Chemical colors & Trunk, upper \& lower limbs & IB & MF & MF & + \\
\hline
\end{tabular}

IHC: Immunohistochemistry; TCR: T-cell receptor gamma gene rearrangement assay; ND: Non diagnostic. 
4.00:1 [14-20]. Male to Female ratio was about 1.00 $1.4: 1$ in studies performed in some cities of Iran (Mashhad, Tabriz and Tehran) [21-23]. In present study this ratio is $1: 1.57$ that is similar to our previous study on incidence rate of MF in Isfahan with male: Female ratio of $3: 4(1: 1.33)$ [24]. These ratios are completely in contrast to other studies. This difference might be due to ethnic group diversity, however to identify the causes of this difference, studies with more patients should be done.

Although MF usually affect older adults with median age of more than 50 years $[1,25,26]$, it was lower in study in Singapore (33 years) [27]. The mean age of patients in a study in Kuwait was 35.2 years [28]. Their results are similar to our study with median of 34.5 years. It seems the age of disease presentation in Asian countries is lower, in contrast to western studies.

Approximately $80 \%$ of MF patients present in early stages (IA, IB and ПА) [15,20,29]. In agreement to other studies, $88.9 \%$ of our patients were in stages IA and IB.

T-cell clonality was present in about $70 \%(50 \%-100 \%)$ of the biopsies diagnosed as MF [30-33]; this was 28.5\% in a study in Hong Kong [20]. In current study $61.1 \%$ of cases showed clonality.

In present study high percentages of patients (38.9\%) were from an agricultural area near to Isfahan (Flavarjan). A reason for this could be closeness of this city to Isfahan, so they can come to Isfahan easily; another might be environmental pollution due to huge industries near that area because according to previous studies environmental exposure to chronic antigenic stimulation (e.g., industrial chemicals, metals, and herbicides/pesticides) may have a causative role $[8,10,34]$.

Occupations involving sun exposure increases the risk of MF [35]; but in this study $66.66 \%$ of patients hadn't had remarkable exposure to sun, radiations or chemicals, although we hadn't detail history of the patients' exposures.

In a study in the United States, CTCL incidence rate correlated with high physician density, family income and higher education that were related to more access to health care. They also found higher incidence rate of MF in blacks and concluded that immunogenetics or interaction of genetic susceptibility and the environment in CTCL, may have a role in MF incidence [18]. In our study majority of the patients were educated up to the high school degree and commonly were housekeepers (women) and workers or salesmen (men).

In conclusion most of our patients presented in early stages that were similar to other studies, while male: female ratio is different from other studies.

\section{Acknowledgements}

We thank Research Department of Isfahan University of
Medical Sciences for their, financial support and Mrs hassankhani and other Alzahra dermatology clinic staff, for their contribution in this study.

\section{REFERENCES}

[1] S. R. Parker and J. V. Bethaney, "Cutaneous T Cell Lymphoma-Mycosis Fungoides and Sezary Syndrome: An Update," G Ital Dermatol Venereol, Vol. 144, No. 4, 2009, pp. 467-485.

[2] E. Samuelson, "Cutaneous T-Cell Lymphomas," Seminars in Oncology Nursing, Vol. 14, No. 4, 1998, pp. 293 301. doi:10.1016/S0749-2081(98)80007-7

[3] M. A. Weinstock and B. Gardstein, "Twenty-Year Trends in the Reported Incidence of Mycosis Fungoides and Associated Mortality," American Journal of Public Health, Vol. 89, No. 8, 1999, pp. 1240-1244. doi:10.2105/AJPH.89.8.1240

[4] S. P. Patel and O. A. Holtermann, "Mycosis Fungoides: An Overview," Journal of Surgical Oncology, Vol. 22, No. 4, 1983, pp. 221-227. doi:10.1002/jso.2930220403

[5] S. M. Worobec-Victor, "Cutaneous T Cell Lymphoma," New Jersey Medicine, Vol. 86, No. 5, 1989, pp. 395-400.

[6] N. Pimpinelli, E. A. Olsen, M. Santucci, E. Vonderheid, A. C. Haeffner, S. Stevens, et al., "Defining Early Mycosis Fungoides," Journal of the American Academy of Dermatology, Vol. 53, No. 6, 2005, pp. 1053-1063. doi:10.1016/j.jaad.2005.08.057

[7] H. S. Zackheim and T. H. McCalmont, "Mycosis Fungoides: The Great Imitator," Journal of the American Academy of Dermatology, Vol. 47, No. 6, 2002, pp. 914918. doi:10.1067/mjd.2002.124696

[8] M. M. Morales-Suarez-Varela, J. Olsen, P. Johansen, L. Kaerlev, P. Guenel, P. Arveux, et al., "Occupational Risk Factors for Mycosis Fungoides: A European Multicenter Case-Control Study," Journal of Occupational and Environmental Medicine, Vol. 46, No. 3, 2004, pp. 205-211. doi:10.1097/01.jom.0000116819.01813.8c

[9] A. S. Whittemore, E. A. Holly, I. M. Lee, E. A. Abel, R. M. Adams, B. J. Nickoloff, et al., "Mycosis Fungoides in Relation to Environmental Exposures and Immune Response: A Case-Control Study," Journal of the National Cancer Institute, Vol. 81, No. 20, 1989, pp. 1560-1567. doi:10.1093/jnci/81.20.1560

[10] Y. Wohl and E. Tur, "Environmental Risk Factors for Mycosis Fungoides," Current Problems in Dermatology, Vol. 35, 2007, pp. 52-64. doi:10.1159/000106410

[11] S. H. Swerdlow, E. Campo, N. L. Harris, E. S. Jaffe, A. S. Pileri, H. Stein, et al., "WHO Classification of Tumours of Haemopoietic and Lymphatic Tissue," IARC Press, Lyon, 2008.

[12] E. Olsen, E. Vonderheid, N. Pimpinelli, R. Willemze, Y. Kim, R. Knobler, et al., "Revisions to the Staging and Classification of Mycosis Fungoides and Sezary Syndrome: A Proposal of the International Society for Cutaneous Lymphomas (ISCL) and the Cutaneous Lymphoma Task Force of the European Organization of Research and Treatment of Cancer (EORTC)," Blood, Vol. 110, No. 6, 
2007, pp. 1713-1722. doi:10.1182/blood-2007-03-055749

[13] J. J. van Dongen, A. W. Langerak, M. Bruggemann, P. A. Evans, M. Hummel, F. L. Lavender, et al., "Design and Standardization of PCR Primers and Protocols for Detection of Clonal Immunoglobulin and T-Cell Receptor Gene Recombinations in Suspect Lymphoproliferations: Report of the BIOMED-2 Concerted Action BMH4-CT983936," Leukemia, Vol. 17, No. 12, 2003, pp. 2257-2317. doi:10.1038/sj.leu.2403202

[14] M. W. Lee, "Characteristics of Cutaneous Lymphomas in Korea," Clinical and Experimental Dermatology, Vol. 28, No. 6, 2003, pp. 639-646. doi:10.1046/j.1365-2230.2003.01374.x

[15] C. Assaf, S. Gellrich, M. Steinhoff, D. Nashan, F. Weisse, E. Dippel, et al., "Cutaneous Lymphomas in Germany: An Analysis of the Central Cutaneous Lymphoma Registry of the German Society of Dermatology (DDG)," Journal der Deutschen Dermatologischen Gesellschaft, Vol. 5, No. 8, 2007, pp. 662-668. doi:10.1111/j.1610-0387.2007.06337.x

[16] T. Ishiji, Y. Takagi and M. Niimura, "Cutaneous Lymphomas in Tokyo: Analysis of 62 Cases in A Dermatology Clinic," International Journal of Dermatology, Vol. 40, No. 1, 2001, pp. 37-40.

[17] N. McFadden, A. Nyfors, G. Tanum, A. Granholt, P. Helme and G. Kavli, "Mycosis Fungoides in Norway 1960-1980. A Retrospective Study," Acta Derm Venereol Suppl (Stockh), Vol. 109, 1983, pp. 1-13.

[18] V. D. Criscione and M. A. Weinstock, "Incidence of $\mathrm{Cu}-$ taneous T-Cell Lymphoma in the United States, 19732002," Archives of Dermatology, Vol. 143, No. 7, 2007, pp. 854-859. doi:10.1001/archderm.143.7.854

[19] K. A. Gurney and R. A. Cartwright, "Increasing Incidence and Descriptive Epidemiology of Extranodal NonHodgkin lymphoma in Parts of England and Wales," The Hematology Journal, Vol. 3, No. 2, 2002, pp. 95-104. doi:10.1038/sj.thj.6200154

[20] L. S. Ku and K. K. Lo, "Mycosis Fungoides-A Retrospective Study of 40 Cases in Hong Kong," International Journal of Dermatology, Vol. 44, No. 3, 2005, pp. 215220. doi:10.1111/j.1365-4632.2004.02362.x

[21] H. Hamideh, A. Hamideh, G. Farideh and Y. Neda, "Demographic and Clinical Features of Mycosis Fungoides in Tabriz, Iran," Iranian Journal of Medical Sciences, Vol. 34, No. 2, 2009, p. 152.

[22] A. R. Khooei and M. R. Keramat, "Cutaneous Lymphomas and Pseudolymphomas: A Ten-Year Study at Emam Reza and Omid Hospitals in Mashhad, Using Immunohistochemical and New Classification Methods," Iranian Journal of Dermatology, Vol. 31, No. 8, 2005, pp. 201210.

[23] H. M. Manuchehri and M. Rakhshan, "Characteristics of Primary Cutaneous Lymphomas in Tehran, Iran (19982004)," Journal of the European Academy of Dermatology and Venereology, Vol. 20, No. 6, 2006, pp. 758-760. doi:10.1111/j.1468-3083.2006.01536.x

[24] M. Salehi, Z. Azimi, F. Fatemi, P. Rajabi, M. Kazemi and G. Amini, "Incidence Rate of Mycosis Fungoides in Isfa- han (Iran)," The Journal of Dermatology, Vol. 37, No. 8, 2010, pp. 703-707.

doi:10.1111/j.1346-8138.2010.00899.x

[25] E. J. Kim, J. Lin, J. M. Junkins-Hopkins, C. C. Vittorio and A. H. Rook, "Mycosis Fungoides and Sezary Syndrome: An Update," Current Oncology Reports, Vol. 8, No. 5, 2006, pp. 376-386. doi:10.1007/s11912-006-0061-1

[26] P. L. Zinzani, A. J. Ferreri and L. Cerroni, "Mycosis Fungoides," Critical Reviews in Oncology/Hematology, Vol. 65, No. 2, 2008, pp. 172-182. doi:10.1016/j.critrevonc.2007.08.004

[27] E. S. Tan, M. B. Tang and S. H. Tan, "Retrospective 5-Year Review of 131 Patients with Mycosis Fungoides and Sezary Syndrome Seen at the National Skin Centre, Singapore," Australasian Journal of Dermatology, Vol. 47, No. 4, 2006, pp. 248-252. doi:10.1111/j.1440-0960.2006.00290.x

[28] Q. A. Alsaleh, A. Nanda, H. Al-Ajmi, H. Al-Sabah, M. Elkashlan, S. Al-Shemmari, et al., "Clinicoepidemiological Features of Mycosis Fungoides in Kuwait, 19912006," International Journal of Dermatology, Vol. 49, No. 12, 2010, pp. 1393-1398.

[29] R. van Doom, C. W. Van Haselen, et al., "Mycosis Fungoides: Disease Evolution and Prognosis of 309 Dutch Patients," Archives of Dermatology, Vol. 136, No. 4, 2000, pp. 504-510. doi:10.1001/archderm.136.4.504

[30] S. E. Thurber, B. Zhang, Y. H. Kim, I. Schrijver, J. Zehnder and S. Kohler, "T-Cell Clonality Analysis in Biopsy Specimens from Two Different Skin Sites Shows High Specificity in the Diagnosis of Patients with Suggested Mycosis Fungoides," Journal of the American Academy of Dermatology, Vol. 57, No. 5, 2007, pp. 782790. doi:10.1016/j.jaad.2007.06.004

[31] C. Xu, C. Wan, L. Wang, H. J. Yang, Y. Tang and W. P. Liu, "Diagnostic Significance of TCR Gene Clonal Rearrangement Analysis in Early Mycosis Fungoides," Chinese Journal of Cancer, Vol. 30, No. 4, 2011, pp. 264272. doi: $10.5732 /$ cjc. 010.10344

[32] P. F. Hsiao, C. H. Hsiao, Y. C. Lin, M. P. Tseng, T. F. Tsai and S. H. Jee, "Histopathologic-Molecular Correlation in Early Mycosis Fungoides Using T-Cell Receptor Gamma Gene Rearrangement by Polymerase Chain Reaction with Laser Capture Microdissection," Journal of the Formosan Medical Association, Vol. 106, No. 4, 2007 , pp. 265-272. doi:10.1016/S0929-6646(09)60251-5

[33] S. L. Kandolf, B. Cikota, O. Stojadinovic, J. Basanovic, D. Skiljevic, L. Medenica, et al., "TCRgamma Gene Rearrangement Analysis in Skin Samples and Peripheral Blood of Mycosis Fungoides Patients," Acta Dermatovenerol Alp Panonica Adriat, Vol. 16, No. 4, 2007, pp. 149-155.

[34] M. M. Morales-Suarez-Varela, J. Olsen, P. Johansen, L. Kaerlev, P. Guenel, P. Arveux, et al., "Occupational Exposures and Mycosis Fungoides. A European Multicentre Case-Control Study (Europe)," Cancer Causes Control, Vol. 16, No. 10, 2005, pp. 1253-1259. doi:10.1007/s10552-005-0456-6

[35] M. M. Morales-Suarez-Varela, J. Olsen, P. Johansen, L. 
Kaerlev, P. Guenel, P. Arveux, et al., "Occupational Sun Exposure and Mycosis Fungoides: A European Multicenter Case-Control Study," Journal of Occupational and
Environmental Medicine, Vol. 48, No. 4, 2006, pp. 390393. doi:10.1097/01.jom.0000194160.95468.20 